\title{
Mineração
}

\section{Classificação de pilhas de estéril na mineração de ferro}

\section{Mine dump classification in the iron ore mining}

\author{
Giani Aparecida Santana Aragão \\ MSc, Pimenta de Ávila Consultoria Ltda., \\ Nova Lima/MG, Brasil \\ giani.aragao@pimentadeavila.com.br
}

Waldyr Lopes de Oliveira Filho

PhD, Universidade Federal de Ouro Preto, Ouro Preto/MG, Brasil

waldyr@em.ufop.br

\section{Resumo}

O artigo apresenta uma proposta canadense de classificação de pilhas de estéril do ponto de vista da sua estabilidade física. O método baseia-se na avaliação ponderada e semiquantitativa de fatores-chave que podem afetar a estabilidade. Seu resultado permite atribuir uma determinada classe à pilha de acordo com o potencial de instabilidade. Essas classes definem um nível de esforço recomendado para investigação, projeto, construção e monitoramento da pilha. Para a verificação da eficácia do sistema de classificação, foi realizado um estudo de caso diante da realidade da mineração de ferro, na cidade de Nova Lima, Minas Gerais. A execução desse trabalho envolveu uma pesquisa documental e um posterior trabalho de campo, a fim de se aplicar, as informações coletadas sobre as pilhas no sistema de classificação.

O trabalho mostra, também, inovações introduzidas pelos autores sobre o uso do sistema de classificação como meio de atestar a qualidade do manejo das pilhas e de identificar condicionantes de um projeto. O sistema de classificação mostrou que se trata de uma ferramenta muito útil, tanto no planejamento, como também na avaliação de todas as fases da vida de uma pilha.

Palavras-chave: Pilha de estéril, classificação, estabilidade, mineração de ferro.

\section{Abstract}

In this paper a Canadian proposal for waste dumps classification according to their physical stability is presented. The method is based on a semi-quantitative evaluation of key factors affecting the stability of a waste dump, and the result allows assigning a certain class of dump according to their instability potential. These classes define a recommended level of effort for investigation, design, construction and monitoring of the dumps. To check the effectiveness of the classification a case study was carried out in face of the iron ore mining reality, in Nova Lima City, Minas Gerais State. The implementation of this work involved a documentation search followed by field work and analyses in order to apply the collected information about the dumps in the classification.

The work also shows innovations introduced by the Authors about the use of the classification system as a means of assessing the quality of the dumps management and also makes it possible to identify main aspects of a project. The proposed classification system showed that it is a very useful tool for both planning and evaluation of all stages of a waste dump life.

Keywords: Waste Dump, classification, stability, iron ore mining. 


\section{Introdução}

A extração de bens minerais faz surgir uma quantidade expressiva de materiais de pouco ou nenhum valor econômico, como o minério futuro e o estéril. O manejo do minério futuro responde a uma estratégia de negócio: tal minério pode ser aproveitado e, ainda, dar um retorno financeiro. Já a remoção de estéril da área de lavra e a sua disposição final representam apenas custos no desenvolvimento de uma mina com implicações, não só de ordem econômica, mas, também, no que diz respeito à segurança e ao meio ambiente.

Atualmente o manejo criterioso de estéril impõe-se devido a diversos fatores. Entre esses fatores destacam-se o significativo aumento no volume de material movimentado nas operações mineiras, a maior escassez de áreas adequadas à disposição, especialmente em empreendimentos mais antigos, a maior exigência dos órgãos fiscalizadores, principalmente nos aspectos ambientais, e o amplo leque de possibilidades para a utilização futura desses depósitos. Essa situação faz com que seja necessário um esforço maior de planejamento das atividades de projeto, construção, operação e reabilitação das estruturas finais geradas pela movimentação dos estéreis.

No Brasil, o planejamento e o projeto de uma pilha estão sujeitos a aprovações legais, apesar de se exigir muito pouco sobre investigação e projeto. A norma ABNT NBR 13029 (2006) especifica os requisitos mínimos para a elaboração e a apresentação de projeto para disposição de estéril.

Dada a diversidade das pilhas em termos locacionais, porte, tipos de estéril, clima, etc., existe uma carência de orientação dos profissionais que lidam com esses empreendimentos. É preciso que eles estabeleçam um nível adequado de detalhamento dos estudos dessas estruturas. Essa dificuldade pode ser, em parte, resolvida por uma classificação de pilhas. Até o presente momento, não existe, entre nós, uma classificação de pilha de estéril com relação ao seu potencial de perigo/dano, algo mais comum de se ver quando o assunto é barragem. No estado de Minas Gerais, por exemplo, existe uma Deliberação Normativa COPAM (62/2002 alterada para 87/2005) específica para barragens, que as classifica segundo o potencial de dano ambiental.

O presente trabalho procura contribuir para preenchimento dessa lacuna ao trazer os resultados de uma pesquisa que teve como objetivo avaliar um sistema de classificação de pilhas de estéril com vistas a sua utilização em gerenciamento de riscos, planejamento, projeto, construção e monitoramento dessas estruturas. Espera-se que o assunto possa despertar uma discussão de um critério de classificação a ser adotado para as pilhas no Brasil.

\section{Sistema de classificação de pilhas de estéril}

Um sistema de classificação proporciona, em geral, a identificação básica de um produto, estrutura ou processo, que, no caso de uma pilha de estéreis, poderia, por exemplo, informar sobre o seu tipo e a sua configuração. Essas informações facilitam a comunicação e o entendimento entre profissionais interessados em projeto e construção. Além disso, a classificação pode fornecer informações adicionais que permitam prever o provável comportamento interno da pilha (poro pressões, nível de água, etc) e identificar problemas potenciais (condicionantes).

Nesse trabalho, avalia-se um sistema de classificação de pilhas desenvolvido para o governo canadense com base na estabilidade física de uma pilha de estéril (BC Mine Waste Rock Pile Research Committee, 1991). Na elaboração desse sistema, foram enviados questionários a diversos profissionais e empresas de consultoria, indagando sobre fatores que influenciavam a estabilidade das pilhas e sua importância. As informações obtidas foram tratadas de modo a se obter um consenso e daí surgiu o sistema de classificação baseado numa pontuação ponderada daqueles pontos-chave e numa categorização do potencial de ruptura das pilhas em classes.

Esse sistema de classificação é uma ferramenta que pode ser utilizada em to- das as fases da vida de uma pilha, desde o seu planejamento. Ela propicia realizar classificações preliminares dos possíveis locais para disposição do estéril, tornando possíveis comparações entre esses locais, quanto ao potencial de instabilidade, e estabelecendo o nível de esforço de investigação, projeto, construção e monitoramento necessários para cada local de acordo com a cada classe encontrada.

O sistema de Classificação consta de duas partes principais, a saber: Avaliação de Estabilidade e Classificação de Pilha. Um complemento à Classificação é o que aqui se denomina Verificação de Enquadramento de Classe.

A Avaliação de Estabilidade da pilha trata-se de uma metodologia semiquantitativa para avaliar o potencial de instabilidade de pilhas com base em fatores-chave. A Tabela 1 lista esses fatores, sendo as três primeiras colunas referentes ao sistema de classificação propriamente dito, compreendendo a descrição, o grau ou intensidade de cada um e a ponderação sugerida. As outras colunas subsequentes apresentam exemplo de classificação dentro de um estudo de caso, que será discutido no item 3.

É importante ressaltar que a atividade de classificar segundo a Tabela 1 permite, também, identificar aspectos relevantes da pilha naqueles fatores onde a pontuação alcançada é máxima (200 ou
100 pontos). Essa observação é apontada no estudo de caso (item 3).

Com a pontuação alcançada, a pilha é, então, classificada em uma das quatro categorias de estabilidade conforme a Tabela 2. Essas categorias ou classes definem um nível de esforço recomendado para investigação, projeto e construção da pilha, ou seja, a qualidade do manejo de estéril. Quanto maior a classe, maior o nível de esforço recomendado. É bom que se esclareça, que ao ser colocada numa categoria, por exemplo, classe III ou IV, não significa que a pilha vai romper ou está com uma estabilidade precária e, sim, qual o potencial de perigo ou dano associado, traduzindo a qualidade de manejo desejado àquela classe em que ela foi classificada.

A Verificação de Enquadramento da Classe é uma etapa complementar dentro do sistema de classificação, onde é analisado se o manejo de estéril previsto ou realizado é compatível com a classificação, ou seja, avalia-se se uma pilha, por exemplo, classe III, está sendo tratada como tal, ou como uma classe diferente. Essa etapa não existe na proposta original da classificação, mas se julgou necessária para responder à questão sobre a qualidade da gestão do manejo de estéreis da pilha classificada. Ela será também apresentada no estudo de caso a seguir. 


\begin{tabular}{|c|c|c|c|c|c|c|c|}
\hline \multirow{2}{*}{\multicolumn{2}{|c|}{$\begin{array}{l}\text { Fatores-chave } \\
\text { que afetam a } \\
\text { estabilidade }\end{array}$}} & \multirow{2}{*}{\multicolumn{2}{|c|}{ Faixa de Condições ou Descrições }} & \multirow{2}{*}{ 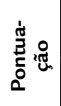 } & \multicolumn{3}{|c|}{$\begin{array}{c}\text { Pontuação } \\
\text { Pilhas (exemplo) }\end{array}$} \\
\hline & & & & & Grota & Capão & Grota \\
\hline \multirow{10}{*}{ 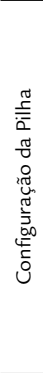 } & \multirow{4}{*}{$\begin{array}{l}\text { Altura } \\
\text { da } \\
\text { Pilha }\end{array}$} & & $<50 \mathrm{~m}$ & 0 & \multirow{4}{*}{50} & \multirow{4}{*}{200} & \multirow{4}{*}{200} \\
\hline & & & $50 m-100 m$ & 50 & & & \\
\hline & & & $100 m-200 m$ & 100 & & & \\
\hline & & & $>200 \mathrm{~m}$ & 200 & & & \\
\hline & \multirow{3}{*}{$\begin{array}{c}\text { Volume } \\
\text { da } \\
\text { Pilha }\end{array}$} & Pequeno & $<1 \times 10^{6} \mathrm{~m}^{3} /$ banco & 0 & \multirow{3}{*}{0} & \multirow{3}{*}{50} & \multirow{3}{*}{50} \\
\hline & & Médio & $1-50 \times 10^{6} \mathrm{~m}^{3} /$ banco & 50 & & & \\
\hline & & Grande & $>50 \times 10^{6} \mathrm{~m}^{3} /$ banco & 100 & & & \\
\hline & \multirow{3}{*}{$\begin{array}{l}\text { Inclina- } \\
\text { ção } \\
\text { do } \\
\text { Talude }\end{array}$} & Suave & $<26^{\circ}$ & 0 & \multirow{3}{*}{0} & \multirow{3}{*}{0} & \multirow{3}{*}{0} \\
\hline & & Moderado & $26^{\circ}-35^{\circ}$ & 50 & & & \\
\hline & & Íngreme & $>35^{\circ}$ & 100 & & & \\
\hline \multirow{4}{*}{\multicolumn{2}{|c|}{$\begin{array}{c}\text { Inclinação } \\
\text { de Fundação }\end{array}$}} & Suave & $<10^{\circ}$ & 0 & \multirow{4}{*}{0} & \multirow{4}{*}{0} & \multirow{4}{*}{0} \\
\hline & & Moderada & $10^{\circ}-25^{\circ}$ & 50 & & & \\
\hline & & Íngreme & $25^{\circ}-32^{\circ}$ & 100 & & & \\
\hline & & Extrema & $>32^{\circ}$ & 200 & & & \\
\hline \multirow{3}{*}{\multicolumn{2}{|c|}{$\begin{array}{c}\text { Grau } \\
\text { de } \\
\text { Confinamento }\end{array}$}} & Confinado & $\begin{array}{l}\text { - Talude côncavo em planta ou seção; } \\
\text { - Aterros em vale ou transversais a um vale, pé de talude em } \\
\text { contato com a parede oposta do vale; } \\
\text {-Ravinas em forma de dente de serra suavisando a inclunação } \\
\text { de fundação. }\end{array}$ & 0 & \multirow{3}{*}{50} & \multirow{3}{*}{50} & \multirow{3}{*}{50} \\
\hline & & $\begin{array}{l}\text { Moderadamente } \\
\text { confinado }\end{array}$ & $\begin{array}{l}\text { - Bancos ou terraços naturais nos taludes; } \\
\text { - Taludes com inclinação uniforme, limitados por topografia } \\
\text { natural diversificada; } \\
\text {-Empilhamento de estéreis em encostas, em vales abertos, ou } \\
\text { transversais a vales. }\end{array}$ & 50 & & & \\
\hline & & $\begin{array}{l}\text { Sem } \\
\text { Confinamento }\end{array}$ & $\begin{array}{l}\text { - Talude convexo em planta ou seção; } \\
\text { - Aterros de encosta ou aterros de crista sem confinamento na } \\
\text { base; } \\
\text { - Sem rafinas ou bancos para auxiliar a construção. }\end{array}$ & 100 & & & \\
\hline \multirow{3}{*}{\multicolumn{2}{|c|}{$\begin{array}{l}\text { Tipos } \\
\text { de } \\
\text { Fundação }\end{array}$}} & Competente & $\begin{array}{l}\text { - Materiais de Fundação tão ou mais resistentes que os da pilha; } \\
\text { - Não sujeita a efeitos adversos da poropressão; } \\
\text { - Sem estruturas geológicas desfavoráveis. }\end{array}$ & 0 & & & \\
\hline & & Intermediária & $\begin{array}{l}\text { - Intermediária entre competente e fraca; } \\
\text { - Ganho de resistência do solo com adensamento; } \\
\text { - Dissipação do excesso de propressões com o controle da taxa de } \\
\text { carregamento. }\end{array}$ & 100 & 100 & 100 & 100 \\
\hline & & Fraca & $\begin{array}{l}\text { - Capacidade de suporte limitada, solos moles; } \\
\text { - Sujeita a excessos de poropressão devido ao carregamento; } \\
\text { - Condições adversas de água subterrânea, surgências ou } \\
\text { infiltrações; } \\
\text {.Baixa resistência ao cisalhamento, com alto potencial de } \\
\text { liquefação. }\end{array}$ & 200 & & & \\
\hline & & Alta & $\begin{array}{l}\text { - Resistente, durável } \\
\text { - Menos que } 10 \% \text { de finos }\end{array}$ & 0 & & & \\
\hline & $\begin{array}{l}\text { alidade } \\
\text { material } \\
\text { la pilha }\end{array}$ & Moderada & $\begin{array}{l}\text { - Moderadamente resistente, durabilidade variável; } \\
\text { - } 10 \text { a } 25 \% \text { de finos }\end{array}$ & 100 & 100 & 100 & 200 \\
\hline & & Pobre & $\begin{array}{l}\text { - Predominância de rochas fracas de baixa durabilidade } \\
\text { - Mais que } 25 \% \text { de finos, material de cobertura (capeamento) }\end{array}$ & 200 & & & \\
\hline & & Favorável & $\begin{array}{l}\text { - Bancos ou camadas não muito espessos ( }<25 m \text { de espessura), } \\
\text { plataformas largas; } \\
\text { - Disposição ao longo das curvas de nível } \\
\text { - Construção ascendente } \\
\text { - Wrap-arounds ou terraços }\end{array}$ & 0 & & & \\
\hline & $\begin{array}{l}\text { Étodo de } \\
\text { nstrução }\end{array}$ & Misto & $\begin{array}{l}\text { - Bancos ou bancadas moderadamente espessas }(25 \mathrm{~m} \text { - } 50 \mathrm{~m}) \\
\text { - Métodos mistos de construção }\end{array}$ & 100 & 0 & 0 & 0 \\
\hline & & Dsfavorável & $\begin{array}{l}\text { - Bancos ou camadas muito espessas ( }>50 \mathrm{~m}) \text {, plataforma estreita } \\
\text { (aterro na forma de pontões) } \\
\text { - Disposição abaixo da linha de queda do talude; } \\
\text { - Construção descendente }\end{array}$ & 200 & & & \\
\hline & & Favorável & $\begin{array}{l}\text { - Baixas pressões piezométricas, nenhuma surgência na fundação; } \\
\text { - Improvável desenvolvimento de superfície freática no interior da } \\
\text { pilha; } \\
\text { - Precipitação limitada; } \\
\text { - Infiltração mínima dentro da pilha; } \\
\text { - Nenhuma camada de neve ou gelo na pilha ou fundação }\end{array}$ & 0 & & & \\
\hline $\begin{array}{r}\text { Co } \\
\text { piezo } \\
\text { e cli }\end{array}$ & $\begin{array}{l}\text { ndições } \\
\text { ométricas } \\
\text { limáticas }\end{array}$ & Intermediária & $\begin{array}{l}\text { - Pressões piezométricas moderadas, algumas infiltrações na } \\
\text { fundação; } \\
\text { - Desenvolvimento limitado da superfície freática na pilha; } \\
\text { - Precipitação moderada; } \\
\text { - Alta infiltração no interior da pilha; } \\
\text { - Lentes ou camadas descontínuas denve ou gelo na pilha ou na } \\
\text { fundação; }\end{array}$ & 100 & 100 & 100 & 200 \\
\hline & & Desfavorável & $\begin{array}{l}\text { - Altas pressões piezométricas, surgências na fundação; } \\
\text { - Alta precipitação; } \\
\text { - Significativo potencial de desenvolvimento de superfície freática ou } \\
\text { lençol suspenso no interior da pilha. }\end{array}$ & 200 & & & \\
\hline & & Baixa & $\begin{array}{l}-<25 \mathrm{~m}^{3} / \text { banco por metro linear de crista por dia; } \\
\text { - Taxa de avanço da crista }<0.1 \mathrm{~m} \text { por dia. }\end{array}$ & 0 & & & \\
\hline $\begin{array}{r}T_{c} \\
\text { decor }\end{array}$ & $\begin{array}{l}\text { axa de } \\
\text { mposição }\end{array}$ & Moderada & $\begin{array}{l}\text { - } 25 \text { - } 200 \mathrm{~m}^{3} / \text { banco por metro linear de crista por dia; } \\
\text { - Taxa de avanço da crista de } 0.1 \mathrm{~m}-1.0 \mathrm{~m} \text { por dia. } \\
\end{array}$ & 100 & 0 & 0 & 0 \\
\hline & & Alta & $\begin{array}{l}\text { - > } 200 \mathrm{~m}^{3} / \text { banco por metro linear de crista por dia; } \\
\text { - Taxa de avanço da crista > } 1.0 \mathrm{~m} \text { por dia. }\end{array}$ & 200 & & & \\
\hline & & Baixa & Zona de risco sísmico 0 e 1 (escala Richter) & 0 & & & \\
\hline & micidade & Moderada & Zona de risco sísmico 2 e 3 & 50 & 0 & 0 & 0. \\
\hline & & Alta & Zona de risco sísmico 4 ou maior & 100 & & & \\
\hline & & Pontuaçã & máxima possível de estabilidade da pilha: 1.800 & & 350 & 600 & 800 \\
\hline
\end{tabular}

Pontuação de Estabilidade de Pilhas de Estéril e exemplo de aplicação (modificado BC Mine Waste Rock Pile Research Committee, 1991; Aragão, 2008) 


\begin{tabular}{|c|c|c|c|c|}
\hline $\begin{array}{c}\text { Classificação } \\
\text { da estabi- } \\
\text { lidade }\end{array}$ & $\begin{array}{l}\text { Potencial } \\
\text { de Ruptura }\end{array}$ & $\begin{array}{l}\text { Nível de Esforço Recomendado } \\
\text { para Investigação, Projeto e Construção }\end{array}$ & $\begin{array}{c}\text { Faixa de } \\
\text { pontuaç̧ão }\end{array}$ & $\begin{array}{c}\text { Classificação } \\
\text { Pilhas } \\
\text { Exemplo }\end{array}$ \\
\hline 1 & Desprezível & $\begin{array}{l}\text { - Reconhecimento básico do local, documentação de } \\
\text { referência; } \\
\text { - Programa mínimo de ensaios de laboratório; } \\
\text { - Rotina de checagem de estabilidade, possivelmente } \\
\text { usando ábacos; } \\
\text { - Restrições mínimas na construção; } \\
\text { - Monitoramento apenas visual. }\end{array}$ & $<300$ & \\
\hline II & Baixo & $\begin{array}{l}\text { - Investigaçãa completa do local; } \\
\text { - Poços de inspeção, amostragem pode ser obrigatória; } \\
\text { - Programa limitado de ensaios de laboratório; } \\
\text { - Estabilidade pode ou não influenciar o projeto; } \\
\text { - Análise básicas de estabilidade obrigatória; } \\
\text { - Certas restriç̃̃es na construção; } \\
\text { - Monitoramento visual e de instrumentos de rotina. }\end{array}$ & $300-600$ & Grota Fria \\
\hline III & Moderado & $\begin{array}{l}\text { - Investigação detalhada do local; } \\
\text { - Poços de inspeção obrigatórios, ou outras } \\
\text { investigações de superfície podem ser obrigatórias; } \\
\text { - Programa detalhado de ensaios de laboratório, } \\
\text { incluindo propriedades-índice, resistência ao } \\
\text { cisalhamento e durabilidade provavelmente } \\
\text { obrigatórios; } \\
\text { - Estabilidade influencia e pode controlar o projeto; } \\
\text { - Análise de estabilidade detalhada, possivelmente } \\
\text { estudos paramétricos, obrigatórios; } \\
\text { - Projeto básico pode ser obrigatório para aprovação/ } \\
\text { permissão; } \\
\text { - Restrições moderadas na construção (ex. taxa de } \\
\text { carregamento limitada, espessuras das camadas, qualidade } \\
\text { do material, drenagem superficial adequada, etc.); } \\
\text { - Monitoramento detalhado de instrumentação para } \\
\text { confirmar projeto, documentar performance e estabelecer } \\
\text { limites de carregamento. }\end{array}$ & $\begin{array}{l}600- \\
1200\end{array}$ & $\begin{array}{l}\text { Capão } \\
\text { da Serra } \\
\text { Grota } 0\end{array}$ \\
\hline IV & Alto & $\begin{array}{l}\text { - Investigação detalhada do local em etapas; } \\
\text { - Poços de inspeção e possíveis trincheiras, obrigatórios; } \\
\text { - Sondagens e outras possíveis investigações subsuperficiais } \\
\text { provavelmente obrigatória; } \\
\text { - Amostragem indeformada provavelmente obrigatória; } \\
\text { - Programa detalhado de ensaios, incluindo propriedades- } \\
\text { índice, resistência ao cisalhamento e durabilidade } \\
\text { provavelmente obrigatórios; } \\
\text { - Considerações sobre estabilidade essesnciais; } \\
\text { - Análises de estabilidade detalhadas, possivelmente incluindo } \\
\text { estudos paramétricos e avaliações completas de alternativas } \\
\text { provavelmente obrigatórias; } \\
\text { - Projeto básico possivelmente obrigatório para aprovação/ } \\
\text { permissão; } \\
\text { - Restrições severas na construção (ex. taxas limite de } \\
\text { carregamento, espessuras das camadas, qualidade do } \\
\text { material, drenagem superficial, etc.); } \\
\text { - Monitoramento detalhado de instrumentação para } \\
\text { confirmar projeto, documentar performance e estabelecer } \\
\text { limites de carregamento. }\end{array}$ & $>200$ & \\
\hline
\end{tabular}

\section{Estudo de Caso}

O sistema de classificação introduzido anteriormente foi examinado nessa pesquisa através de estudo de caso nas pilhas de estéreis da VALE,

\section{Características gerais das pilhas}

A primeira etapa do estudo de classificação das pilhas compreendeu uma pesquisa documental sobre os fatoreschave (Tabela 1) para cada um dos 34 empreendimentos mineiros. Iniciou-se com os documentos em meio físico. Foram analisados documentos como: projetos básicos, projetos executivos, relatórios de reuniões, relatórios de consultores, mapas, croquis, relatórios de instrumentos, nos complexos mineiros de Vargem Grande e Paraobebas, em Minas Gerais, mais especificamente no Quadrilátero Ferrífero.

relatórios de investigação de campo, etc. Em seguida, passou-se a análise dos documentos em meio eletrônico. Ao concluir o trabalho, os dados foram computados e organizados de forma estruturada em planilhas eletrônicas. Para cada mina, foi feita uma planilha e, dentro dessas planilhas, foram colocadas as pilhas das respectivas minas, contendo as informações sobre as variáveis pesquisadas.
Tabela 2

Classificação da estabilidade da pilha e nível de esforço recomendado (modificado BC Mine Waste Rock Pile Research Committee, 1991). 


\section{Trabalho de Campo}

Ao finalizar a análise de todos os dados, foram separadas as pilhas que possuíam o maior número de informações necessárias à classificação, evitando-se inferências. As pilhas selecionadas foram Grota Fria (desativada) e Capão da Serra (em operação), da mina do Tamanduá, e

Tabela 3

Análise das Características das Pilhas Estudadas

\section{Classificação das Pilhas}

As pilhas escolhidas foram analisadas pela Tabela 1 , sendo a pontuação dos fatores de cada uma das pilhas mostrada naquela tabela (três últimas colunas da esquerda). As pilhas foram classificadas dentro de uma categoria (classe) de acordo com a Tabela 2. A pi-
Grota 0 (em operação de retomada, alteamento), da mina da Mutuca.

Além do trabalho de escritório, realizaram-se visitas ao campo àquelas estruturas de modo a se obter um conhecimento da situação real das pilhas, do plano operacional, o "as built" de construção, e a se ter acesso a relatórios locais, resultados de instrumentação e outras informações por meio de comunicação pessoal. Essa atividade foi muito útil para complementar e para validar os dados coletados na fase de escritório (pesquisa documental).

\begin{tabular}{|c|c|c|}
\hline & Dados Verificados & $\%$ \\
\hline \multirow{3}{*}{$\begin{array}{l}\text { Fontes de Informações } \\
\text { Coletadas }\end{array}$} & Projeto Executivo & 40 \\
\hline & Análise de risco - FMEA & 10 \\
\hline & Documentos diversos & 60 \\
\hline \multirow{3}{*}{ Situação das Pilhas } & Desativada & 10 \\
\hline & Atividade & 36 \\
\hline & Projeto & 16 \\
\hline Método Construtivo & Construção Ascendente & 100 \\
\hline \multirow{4}{*}{ Tipo de Pilha } & Aterro em Vale & 70 \\
\hline & Aterro em Encosta & 16 \\
\hline & Aterro em Crista & 7 \\
\hline & Pilha & 7 \\
\hline \multirow{3}{*}{ Altura Geral da Pilha } & $<100$ & 13 \\
\hline & $100 \mathrm{~m}$ a $200 \mathrm{~m}$ & 47 \\
\hline & $>200 m$ & 40 \\
\hline \multirow{2}{*}{ Altura dos Bancos } & $10 \mathrm{~m}$ a $20 \mathrm{~m}$ & 20 \\
\hline & $20 m$ & 80 \\
\hline \multirow{3}{*}{$\begin{array}{l}\text { Ângulo de Inclinação } \\
\text { Geral dos Taludes }\end{array}$} & $21^{\circ}$ & 47 \\
\hline & $21^{\circ}$ a $23^{\circ}$ & 27 \\
\hline & $<21^{\circ}$ & 26 \\
\hline \multirow{2}{*}{ Ângulos entre bancos } & $26^{\circ}-26,6^{\circ}$ & 85 \\
\hline & $29^{a}$ & 15 \\
\hline Qualidade do Material & $\begin{array}{l}\text { Filitos, xistos, itabiritos pobres, quartzitos, cangas e rochas } \\
\text { básicas em diversos estados de alteração }\end{array}$ & 90 \\
\hline Monitoramento & Inspeção e instrumentos & 100 \\
\hline
\end{tabular}

lha do Capão da Serra obteve seiscentos pontos, no limiar de classificação entre classe II e classe III, sendo conservadoramente classificada como classe III, com potencial de ruptura moderado. A pilha da Grota Fria obteve trezentos e cinqüenta pontos, sendo classificada como classe II, com potencial de ruptura baixo. A pilha da Grota 0 obteve oitocentos pontos, sendo classificada como classe III, com potencial de ruptura moderado.

De acordo com a Tabela 1, é possível, também, observar que os aspectos

\begin{tabular}{|c|c|c|c|c|c|}
\hline Itens & Descrição & Classe I & Classe II & Classe III & Classe IV \\
\hline \multirow{8}{*}{ Investigação } & Reconhecimento do Local & Básico & Completo & & alhado \\
\hline & Programa de Ensaio & Mínimo & Limitado & & alhado \\
\hline & \multirow{2}{*}{ Poço de Inspeção } & & Opcional & \multirow{2}{*}{\multicolumn{2}{|c|}{ Obrigatório }} \\
\hline & & & Obrigatório & & \\
\hline & \multirow{2}{*}{$\begin{array}{l}\text { Amostragem } \\
\text { Indeformada }\end{array}$} & & & \multicolumn{2}{|c|}{ Opcional } \\
\hline & & & & \multicolumn{2}{|c|}{ Obrigatório } \\
\hline & \multirow{2}{*}{ Sondagens } & & & & Opcional \\
\hline & & & & & Obrigatório \\
\hline \multirow{2}{*}{ Projeto } & Análise de Estabilidade & Ábacos & Básica & \multicolumn{2}{|c|}{ Detalhada } \\
\hline & Projeto Básico & & & \multicolumn{2}{|c|}{ Obrigatório } \\
\hline \multirow[b]{2}{*}{ Construção } & Restrições na Construção & Mínima & Algumas & \multicolumn{2}{|c|}{ Moderadas } \\
\hline & Monitoramento & Visual & $\begin{array}{l}\text { Visual/ } \\
\text { Instrumento } \\
\text { Rotina }\end{array}$ & \multicolumn{2}{|c|}{$\begin{array}{l}\text { Monitoramento } \\
\text { Detalhado }\end{array}$} \\
\hline
\end{tabular}


mais relevantes de projeto (condicionantes de projeto) para as três casos estudados, de um modo geral, foram: altura das pilhas, tipo de fundação, qualidade do material da pilha e condições piezométricas e climáticas.

Com a classe definida, passou-se à etapa de se verificar o nível de esforço empregado estava compatível com a classe encontrada. Para a verificação do enquadramento da classe, foi modificada a apresentação da Tabela 2, de modo a tornar mais direta o seu uso nessa nova finalidade. Assim surgiu a
Tabela 4 - Enquadramento de Classe.

No exercício de enquadramento da pilha Grota Fria (classe II) com auxílio, também, de pesquisa documental e de visitas ao campo (itens anteriores), constatou-se que, dos nove itens de avaliação, havia informações sobre seis deles, destacando-se que, nos quesitos de investigação e projeto, o realizado, para esta pilha, estava acima do necessário (nível de classe III e IV).

A pilha Capão da Serra (classe III) também possuía informações em seis itens, chegando a respostas satisfatórias

\section{Conclusão}

O sistema de classificação de pilhas de estéril apresentado parece mostrar-se uma ferramenta muito útil na avaliação de todas as fases da vida de uma pilha, atingindo um nível razoável entre a aplicabilidade e a facilidade no estudo de caso avaliado.

Além da classificação, verificou-se que o método traz, como importante subproduto, a identificação de aspectos relevantes de projeto (condicionantes).

A questão de avaliação de enquadramento de classe foi introduzida como complemento ao sistema original, ampliando o alcance da classificação proposta, permitindo uma constatação ainda que conceitual sobre a qualidade do manejo de estéril na pilha classificada.

O resultado do enquadramento de classe no estudo de caso é apenas indicativo, pois muitos itens não possuíam para atendimento aos requisitos de esforço de uma pilha classe III, ou mesmo classe IV, no que tange a sondagens.

Por fim, a pilha Grota 0 (classe III) possuía informações também em seis itens, todos atendidos na classe III/IV, com exceção de um, marcado em classe superior, ou seja, acima do exigido.

$\mathrm{O}$ enquadramento de classe das pilhas analisadas não foi de todo completo, mas os resultados sugerem que as pilhas foram e/ou estão sendo objeto de um manejo compatível com a classificação.

\section{Referências bibliográficas}

ABNT, ASSOCIAÇÃO BRASILEIRA DE NORMAS TÉCNICAS. Coletânea de normas de mineração e meio ambiente - NBR 13029. Rio de Janeiro, 2006. p. 2-5.

BC MINE WASTE ROCK PILE RESEARCH COMMITTEE. Mined Rock and Overburden Piles. Investigation \& Design Manual. Interim Guidelines, 1991. 128p.

ARAGÃO, G. A. S. Classificação de pilhas de estéril na mineração de ferro. Ouro Preto: Departamento de Engenharia de Minas, Universidade Federal de Ouro Preto, 2008. (Dissertação de Mestrado).

Artigo recebido em 02 de fevereiro de 2010. Aprovado em 12 de novembro de 2010. 